\title{
PRINCIPLES FOR HOW WE TREAT EACH OTHER: EQUITABLE CONVERSATIONS IN OUR EDUCATIONAL AND PERSONAL SPACES
}

\author{
Jennifer Sanguiliano Lonski, Laurinda Lott, \& Hank Van Putten \\ Peace and Justice Institute, Valencia College (USA)
}

\begin{abstract}
Educators have the unique opportunity to promote equity, change, and social justice ideals to an entire generation. Through daily lessons, classroom norms, and beliefs, classroom teachers can disrupt inequity among students. The Peace and Justice Institute (PJI) at Valencia College has worked with approximately 140 educators through the week-long PJI Teachers Academy over the past three years. This workshop explores the basis of the PJI philosophy, the Principles for How We Treat Each Other: Our Practice of Respect and Community Building (PJI Principles), and discusses social justice practices and norms that research indicates support equity and inclusion in the classroom. This workshop will begin with a brief introduction to the Peace and Justice Institute and the presenter backgrounds. Research has indicated that the practice of reading the PJI Principles aloud, discussing them with members of the community, and focusing on application impacts the way we communicate with each other in our personal and professional spaces. In this session participants will read the PJI Principles aloud, hearing the voices of their online community as they discuss the implications of a standard set of norms. Following the initial reading, the presenters will dive deeper into three of the principles, working with participants to explore practical applications of the PJI Principles. With the understanding that social change towards equity and justice can begin with teachers and their classrooms, this workshop will conclude with research regarding personal and professional change related to the PJI Principles. This presentation is open to all participants.
\end{abstract}

Keywords: Equity, inclusive, social justice, education.

\section{Introduction}

Education does not only instruct students on various content areas, but serves as the introduction to societal norms, beliefs, and expectations through curriculum, lessons, and daily interactions. In this way, classrooms and schools can either reproduce social inequity, or act as disruptors of inequity. In order to serve as the latter, educators need to be equipped with the tools requisite to provide a socially just and inclusive education. The Peace and Justice Institute (PJI) at Valencia College has hosted the Teachers Academy for the past three years, working with 140 educators across 40 schools. While focusing on educators, the Teachers Academy is a part of the larger Peace and Justice Institute that has the mission of "Making a difference by intentionally engaging in practices and principles that explore, advocate, and honor the dignity of self, others, and the earth. (Peace and Justice Institute, 2021). PJI has supported local communities for the past 12 years, including development opportunities for nonprofits, city employees, the faith community, police departments, as well as the faculty, staff, and students at Valencia College.

At the core of the PJI philosophy is a series of thirteen Principles for How We Treat Each Other: Our Practice of Respect and Community Building (the PJI Principles, see Table 1). During PJI and Teachers Academy sessions, participants read and discuss the Principles, and apply them to their personal and professional context. Primary, secondary, and higher education institutions alike have implemented the PJI Principles as norms in their classrooms and community. Throughout the course of two research projects, including a doctoral dissertation, Teachers Academy alumni expressed the importance and significance of the Principles in their personal and professional practices (Sanguiliano Lonski, 2020, Sanguiliano \& Mack, 2020). One Teachers Academy alumni, a second-grade teacher, shared in an interview that the most impactful portion of the professional development was

The PJI Principles ... especially number 10, "When things get difficult, turn to wonder." I encourage the students to listen and think before they speak. They may not agree with their friend, but their friend may be going through a difficult time, maybe dad had to go out of town, maybe they didn't have breakfast, could be a million different scenarios. Stop and turn to wonder. How can you help your friend? Principle 10 will change everything! 
When asked about the PJI Principles, a high school teacher explained, "You can always use them. You can use them when you are disciplining or when you're disappointed, or when something nice happens, you can use some with your praise...", while another stated, "I think the most important thing are just the Principles. Because if you do nothing but instill the Principles for How We Treat Each Other, you're going to be fine." Repeatedly, teachers discussed the importance of the PJI Principles in their classrooms, a paradigm shift from the traditional focus of classroom management and educational professional development (Sanguiliano Lonski, 2020).

Table 1. The PJI Principles How We Treat Each Other: Our Practice of Respect and Community Building.

1. Create a hospitable and accountable community. We all arrive in isolation and need the generosity of friendly welcomes. Bring all of yourself to the work in this community. Welcome others to this place and this work, and presume that you are welcomed as well. Hospitality is the essence of restoring community.

2. Listen deeply. Listen intently to what is said; listen to the feelings beneath the words. Strive to achieve a balance between listening and reflecting, speaking and acting.

3. Create an advice free zone. Replace advice with curiosity as we work together for peace and justice. Each of us is here to discover our own truths. We are not here to set someone else straight, to "fix" what we perceive as broken in another member of the group.

4. Practice asking honest and open questions. A great question is ambiguous, personal and provokes anxiety.

5. Give space for unpopular answers. Answer questions honestly even if the answer seems unpopular. Be present to listen not debate, correct or interpret.

6. Respect silence. Silence is a rare gift in our busy world. After someone has spoken, take time to reflect without immediately filling the space with words. This applies to the speaker, as well - be comfortable leaving your words to resound in the silence, without refining or elaborating on what you have said.

7. Suspend judgment. Set aside your judgments. By creating a space between judgments and reactions, we can listen to the other, and to ourselves, more fully.

8. Identify assumptions. Our assumptions are usually invisible to us, yet they undergird our worldview. By identifying our assumptions, we can then set them aside and open our viewpoints to greater possibilities.

9. Speak your truth. You are invited to say what is in your heart, trusting that your voice will be heard and your contribution respected. Own your truth by remembering to speak only for yourself. Using the first person "I" rather than "you" or "everyone" clearly communicates the personal nature of your expression.

10. When things get difficult, turn to wonder. If you find yourself disagreeing with another, becoming judgmental, or shutting down in defense, try turning to wonder: "I wonder what brought her to this place?" "I wonder what my reaction teaches me?" "I wonder what he's feeling right now?

11. Practice slowing down. Simply the speed of modern life can cause violent damage to the soul. By intentionally practicing slowing down we strengthen our ability to extend nonviolence to others - and to ourselves.

12. All voices have value. Hold these moments when a person speaks as precious because these are the moments when a person is willing to stand for something, trust the group and offer something they see as valuable.

13. Maintain confidentiality. Create a safe space by respecting the confidential nature and content of discussions held in the group. Allow what is said in the group to remain there.

\section{Primary objective}

The primary objective for this session is to identify ways the PJI Principles for How We Treat Each Other enhance our personal and professional lives. This workshop is not intended to be a substitute for the 40-hour PJI Teachers Academy professional development session. The weeklong Teachers Academy explores a myriad of topics beyond the Principles including an in-depth analysis of personal beliefs, privilege, and biases, before addressing curricular concerns, understanding Adverse Childhood Experiences (ACEs), inclusive and social justice education, restorative practices, and equity in education. The current workshop serves as an introduction to the PJI Principles, and the beginning of a discussion of equity in educational and personal spaces. 


\section{Workshop design}

This workshop will begin with an introduction of PJI, PJI Teachers Academy, and the presenters. To best replicate the PJI experience, participants will be asked to read the full text of the PJI Principles aloud. It is through hearing the PJI Principles read by different members of the community that the impact and gravity of each Principle can begin to be fully embraced. After reading the principles aloud, the participants will be divided into breakout rooms for moderated discussions on the applications of the PJI Principles in educational, professional, and personal spaces. The presentation will conclude with the breakout sessions rejoining as a centralized group to share highlights from their discussions. The presenters will also review recent research related to PJI Teachers Academy.

\section{References}

Peace and Justice Institute. (2021). PJI Principles How Se Treat Each Other. Retrieved January 18, 2021, from https://valenciacollege.edu/students/peace-justice-institute/who-we-are/principles.php

Peace and Justice Institute. (2021). Who We Are: Our Vision. Retrieved January 18, 2021, from https://valenciacollege.edu/students/peace-justice-institute/who-we-are/

Sanguiliano Lonski, J. (2020). Social Justice, Inclusive Education, and Teacher Agency. (Doctoral dissertation). Retrieved from https://stars.library.ucf.edu/etd2020/281

Sanguiliano, J., \& Mack, R. (2020) A Look Inside: The Peace and Justice Institute Academy for Teachers' Influence on Participant Professionals. Peace and Justice Institute Journal, 10(2), 8-11.Retrieved January 18, 2021 from: https:/valenciacollege.edu/students/peace-justiceinstitute/resources/documents/pji-journal-vol10no2-interactive.pdf 